\title{
Follow-up interval for dental appointments: a randomized clinical trial with children with low caries risk
}

\author{
Gabriela Oliveira BERTI (a) \\ Jenny ABANTO(a) \\ Thais CORDESCHI(a) iD \\ Gabriela Sá OLIVEIRA(a) iD \\ Thiago SAADS(b) iD \\ Marcelo BÖNECKER(a) ID \\ (a) Universidade de São Paulo - USP, School of \\ Dentistry, Department of Pediatric Dentistry \\ and Orthodontics, São Paulo, SP, Brazil. \\ (b) University of Bern, Department of \\ Restorative, Preventive and Pediatric \\ Dentistry, Bern, Switzerland.
}

Declaration of Interests: The authors certify that they have no commercial or associative interest that represents a conflict of interest in connection with the manuscript.

Corresponding Author:

Gabriela Oliveira Berti

E-mail: dragabrielaberti@gmail.com

htps://doi.org/10.1590/1807-3107bor-2021.vol35.0014

Submitted: April 27, 2020

Accepted for publication: July 15, 2020

Last revision: August 20, 2020

\begin{abstract}
The objective of this study was to evaluate the effect of different follow-up consultation intervals on caries incidence in children with low caries risk. The study was composed of 224 children aged between 3 and 5 years and with low risk of caries. The children were randomly allocated into two groups, according to two different follow-up consultation intervals: Group 1 (G1) - 12-month follow-up interval; Group 2 (G2) - 18-month follow-up interval. All oral clinical examinations were performed by a single examiner who was previously calibrated and blinded in relation to the study groups. An external dentist provided the advice on oral hygiene and diet and evaluated the children's socioeconomic conditions. The Chi-square and Mann-Whitney tests were used to evaluate the differences between groups. Poisson regression analyses were performed to assess the association of caries incidence with the other variables. At the end of the study there was a significant difference between the groups regarding initial active lesions $(p=0.012)$, and children in G2 were at a higher risk of developing initial active lesions than those in G1 ( $p=0.047)$. Children who had a higher number of teeth with initial active lesions in the follow-up consultations were at a higher risk of developing cavitated dentin caries $(p=0.001)$. Both follow-up intervals are justifiable. Although significant results have been observed for initial active caries lesions within the 18-month follow-up interval, it should be noted that these lesions can be treated using just preventive measures. Besides, different return interval had no effect in cavitated dentin lesions.
\end{abstract}

Keywords: Pediatric Dentistry; Dental Caries; Child, Preschool.

\section{Introduction}

The determination and effectiveness of the intervals between dental follow-up appointments have been discussed amongst people involved in the promotion of oral health. Recommendations vary between countries and dental health systems around the world, ${ }^{1}$ though a 6-month interval has been traditionally advocated as an acceptable parameter. However, there is no scientific evidence proving that this follow-up interval is effective for preventing tooth decay or that it has a good cost-benefit ratio for both children and adults. ${ }^{1,2}$ 
Regarding children under the age of 5 years, there is little scientific evidence on this issue. A systematic review ${ }^{1}$ showed that, in relation to primary teeth, only one study sought to determine whether a 12- or a 24-month interval would be effective for the prevention of caries in patients at low risk of tooth decay. ${ }^{3}$

Considering that each child has different clinical conditions and treatment needs, pediatric dentists need to establish follow-up strategies to be used in the prevention and treatment of caries. These strategies should be based on the risk of the patient developing further tooth decay. Two systematic reviews discussed the programs for caries risk assessment and they concluded that the evidence is weak and limited, especially for preschool children., 4

In a context where the scientific evidence on the subject is still scarce, conducting well-designed randomized clinical trials becomes important, particularly to provide clearer conclusions about appropriate follow-up intervals and their relationship with the caries incidence. ${ }^{1,2}$ Such studies also provide the basis for a better distribution and targeting of human and financial resources in children's public oral health care programs for a more effective caries prevention program. Given the above, this randomized clinical trial aimed to evaluate the effect of different follow-up intervals on caries incidence in pre-school children with a low risk of tooth decay.

\section{Methodology}

The project adopted a parallel randomized clinical trial (RCT) design and was written according to the CONSORT guidelines for RCTs used in parallel studies. ${ }^{6}$ The project was approved by the Research Ethics Committee of the School of Dentistry of the University of São Paulo (Number: 1.121.869) and was registered at clinicaltrials.gov (NCT02263768).

\section{Participants}

Inclusion criteria and sample size

Children aged between 3 and 5 years, of both genders, who had been living in São Paulo (water fluoridation of $0.7 \mathrm{ppm}$ ) for at least 1 year were considered for the study. They should have had a low caries risk and attend a municipal public school from the Butantã District of São Paulo City. For the children to be considered at low caries risk, they should have presented the following characteristics: a. absence of gingivitis, when their Final Gingival Bleeding Index ${ }^{7}$ was equal to zero (0);

b. absence of plaque, when the simplified plaque index ${ }^{8}$ was regarded as Good $(0.0-1.0)$;

c. absence of active or inactive white spot lesions, absence of cavitated caries, and absence of restored teeth, according to ICDAS (International Caries Detection and Assessment System).,10 The evaluation of the caries lesion activity was conducted according to the additional criteria associated with the ICDAS score. ${ }^{11,12}$

These caries risk criteria were established according to an instrument developed by the Municipal Health Secretariat of São Paulo, based on the risk of dental caries with specific follow-up intervals for different groups..$^{13}$ This instrument is being used in the public dental services of the city of São Paulo, and an adapted version of it was tested in a retrospective cohort study with children from 1 to 12 years old, having shown to be effective for preventing dental caries. ${ }^{14}$

Patients with at least one of the following conditions were excluded: had received professional application of fluoride in the 6 months prior to the study, and with one or more of the following conditions: systemic disease, cognitive disability, motor disability, use of long-term medication in the form of syrups, fixed orthodontic appliance and/or dental development anomalies. Moreover, children who received any kind of professional dental treatment during the study was excluded.

The sample calculation was conducted considering the incidence of caries in primary teeth, as well as cavitated lesions reaching dentin. A difference of -0.90 (4.41) between means ${ }^{3}$ was considered for the increase in the number of caries lesions between the baseline and the 24-month follow-up consultation. A significance level of $5 \%(\alpha=0.05)$ and a power of $80 \%(\beta=0.2)$ were also considered, and a further $30 \%$ was added due to possible drop-outs. A final sample size of 224 children ( $n=112$ for each group) was calculated. 
Selection and randomization into groups

A total of 7 municipal public schools (from a total of 15) in the Butantã District of the city of São Paulo were randomly chosen and invited to participate in the study, but only 5 schools accepted the invitation. Two schools did not accept to participate in the study because they were unwilling to change the children's school routine.

An initial meeting with principals and coordinators was conducted in each school to explain the purpose and design of the study. A meeting was later scheduled with the parents/guardians of all children $(n=597)$ aged between 3 and 5 years. During the meeting, the objectives and study design were explained and questions that arose were clarified. At the end of the meeting, 588 guardians agreed that their children participated in the research and they signed the informed consent forms.

Of a total of 588 children that underwent the initial clinical examination for inclusion criteria, 289 children were excluded. From the remaining 299 eligible children, we randomly selected 224, according to the sample size calculation. The clinical examination was carried out at the school, using a dental headlight, a sterile gauze, a clinical mirror, and periodontal probe. The clinical examination entailed: the Löe's bleeding index, the Greene and Vermillion's simplified plaque index using the disclosing solution Replak (Replak, Dentsply), and the caries index ICDAS. For the latter, the examiner brushed the children's teeth, dried them using a gauze, and examined all tooth surfaces visually and with a ball-point probe.

The cut-off points for detection of caries were registered as $d_{1}$ (initial enamel caries - ICDAS scores 1 and 2), $d_{2}$ (enamel or dentin caries - ICDAS scores $3,4,5$, or 6 ) and $d_{3}$ (cavitated dentin caries - ICDAS scores 5 or 6$).{ }^{15}$ Activity of caries lesions were assessed according to the appearance of the lesion, its location, and tactile sensation upon careful probing. ${ }^{12}$ This was conducted according to the additional criteria associated with ICDAS's scores. ${ }^{11,12}$

Of all the children examined, those who met the clinical inclusion criteria were randomly allocated to two study groups (each with $\mathrm{n}=112$ participants), according to the follow-up interval: a. Group 1 (G1) - 12-month follow-up interval;

b. Group 2 (G2) - 18-month follow-up interval.

Randomization was made using a statistical program (Medcalc software version 12.4.0.0, Ostend, Belgium) that generated a sequence of random numbers, which were sealed in envelopes by an external researcher (JA), and used by another external researcher $(\mathrm{MB})$ to sort the patients into the study groups. The two examiners (GOB and TC) who conducted the clinical evaluations and questionnaire interviews were blinded to the study groups.

\section{Training and calibration of the examiners}

All clinical examinations were performed by a single examiner (GOB) with prior clinical experience in the use of oral clinical indexes, who was previously trained and calibrated. The training and calibration took place in the form of two lectures and clinical discussions, with 5 hours each, on the use of the following indexes: Löe's gingival bleeding index ${ }^{7}$ Greene and Vermillion's simplified plaque index, ICDAS, and the caries lesion activity indicator. ${ }^{10}$ The intra-examiner reproducibility of the bleeding, plaque, caries lesion activity, and dental caries lesion indexes was estimated by comparing the results obtained by the examiner on the first day of analysis and after one week, using Cohen's kappa. The evaluation of the secondary outcomes was conducted by the interviewer (TC), who had been previously trained regarding the correct voice intonation. The interviewer was trained on the use of two questionnaires: socioeconomic and children's oral hygiene.

The intra-examiner reproducibility for the clinical evaluation of caries lesions using ICDAS's criteria was 0.89 . The Kappa value for the assessment of the intra-examiner reproducibility of Greene and Vermillion's simplified index and Löe's index was greater than 0.85 .

\section{Clinical examinations and questionnaires}

All oral clinical evaluations were carried out by the same examiner in all study groups, both at baseline and at the follow-up consultation. Likewise, the questionnaires on socioeconomic conditions and oral health knowledge were also conducted by the same examiner. Clinical examinations and 
questionnaires were conducted twice throughout this study, initially (at baseline) and once at the respective follow-up consultation, after 12 months, for G1, and after 18 months for G2.

The clinical examinations were conducted as previously described: entailing the Löe's bleeding index, the Greene and Vermillion's simplified plaque index, and the ICDAS caries index. The questionnaires on socioeconomic status and oral hygiene were answered by the guardians of the children via telephone interviews, ${ }^{16,17}$ which were carried out one week after the clinical evaluation.

The children's guardians were also given advice on oral hygiene and diet. At baseline, the advice was given prior to the questionnaire on the children's oral hygiene, whereas on the follow-up consultation, the questionnaire was applied before giving the advice. Moreover, at the follow-up consultation we checked with the parents if their child had received any kind of professional dental treatment during the study. The children also received advice on oral hygiene and diet at baseline and in the follow-up consultations, which comprised:

a. Advice on hygiene: The children received advice on hygiene, brushing technique, and brushing frequency, where fluoridated toothpaste and flossing with the parents' supervision was recommended. Both at the baseline and in the follow-up consultation, the children received a free oral hygiene kit containing a children's toothbrush and fluoridated toothpaste with 1,450 ppm sodium monofluorophosphate. Soon after the advice on hygiene, the examiner brushed the child's teeth.

b. Advice on diet: The advice given in relation to diet considered the contents of snacks between main meals and the daily consumption of sucrose to be kept to a maximum of 4 times per day.

\section{Study outcomes}

The primary outcome of the study was caries incidence. This was evaluated as the proportion of children who developed new caries lesions during the study (new lesions at the follow-up consultation). If any participant presented cavitated dentin caries during the study period, they received dental treatment at the schools in the form of restorations with high-viscosity glass ionomer cement.

The secondary outcomes were the socioeconomic conditions and oral hygiene habits.

\section{Statistical analyses}

All data were analyzed using the statistical program STATA 9.0 (Stata Corp. College Station, TX, USA). A $5 \%$ significance level was adopted for all analyses.

Descriptive analyses were conducted to summarize the clinical and socioeconomic characteristics of each study group at baseline, with the purpose of assessing to what extent the groups were comparable in the beginning of the study. The Chi-square test was used to evaluate the differences in relation to socioeconomic conditions, hygiene habits, and the proportion of children with caries (d1, d2, and d3) between the study groups and between all children who remained in each group and those who were lost in the follow-up. Considering that the quantitative data did not show adherence to the normal curve, Mann-Whitney tests were used to assess the differences in the mean number of teeth with dental caries (d1, d2 and d3) between the study groups, and paired-sample Wilcoxon tests were conducted to compare these outcomes between baseline and follow-up consultations within each study group.

Poisson regression analyses with robust variance were performed to evaluate the association between caries incidence with the explanatory variables, which included: study groups, the secondary outcomes, as well as clinical conditions at baseline and follow-up visits, and the socioeconomic conditions at baseline. Two regression analyses were made, considering two cut-off points for caries incidence: a) incidence of new active non-cavitated caries lesions (active d1); b) incidence of new cavitated dentin caries lesions (d3). For both regression analyses, initial non-adjusted univariate regressions were made for the association between caries incidence and each explanatory variable. From the non-adjusted analysis, we selected all variables with $p$-value $<0.20$ to be included in the final adjusted multivariate model. For the variates to remain in the latter model, they had to have a final p-value $<0.05$. The relative risks (RR) and their 95\% confidence intervals $(95 \% \mathrm{CI})$ are reported. 


\section{Results}

The total number of participants included was 224 children, 112 in each study group (G1 and G2). The children's recruitment was carried out from March to April 2015, and follow-up examinations were made according to the study design. The first follow-up consultations of the children in G1 was conducted in March 2016 and for the G2 in October 2016. Of the
224 children included and randomized at the beginning of the study, 210 remained until the end (sample loss rate $=6.25 \%$ ), 107 in G1 and 103 in G2. The reasons for the loss to follow-up were: 4 children from G1 and 5 from G2 changed schools, and 1 child from G1 and 4 children from G2 could not be contacted (Figure 1). No child received dental care by other professional during the study. The vast majority of the questionnaires were answered by mothers (94.8\%).

\section{Inclusion}

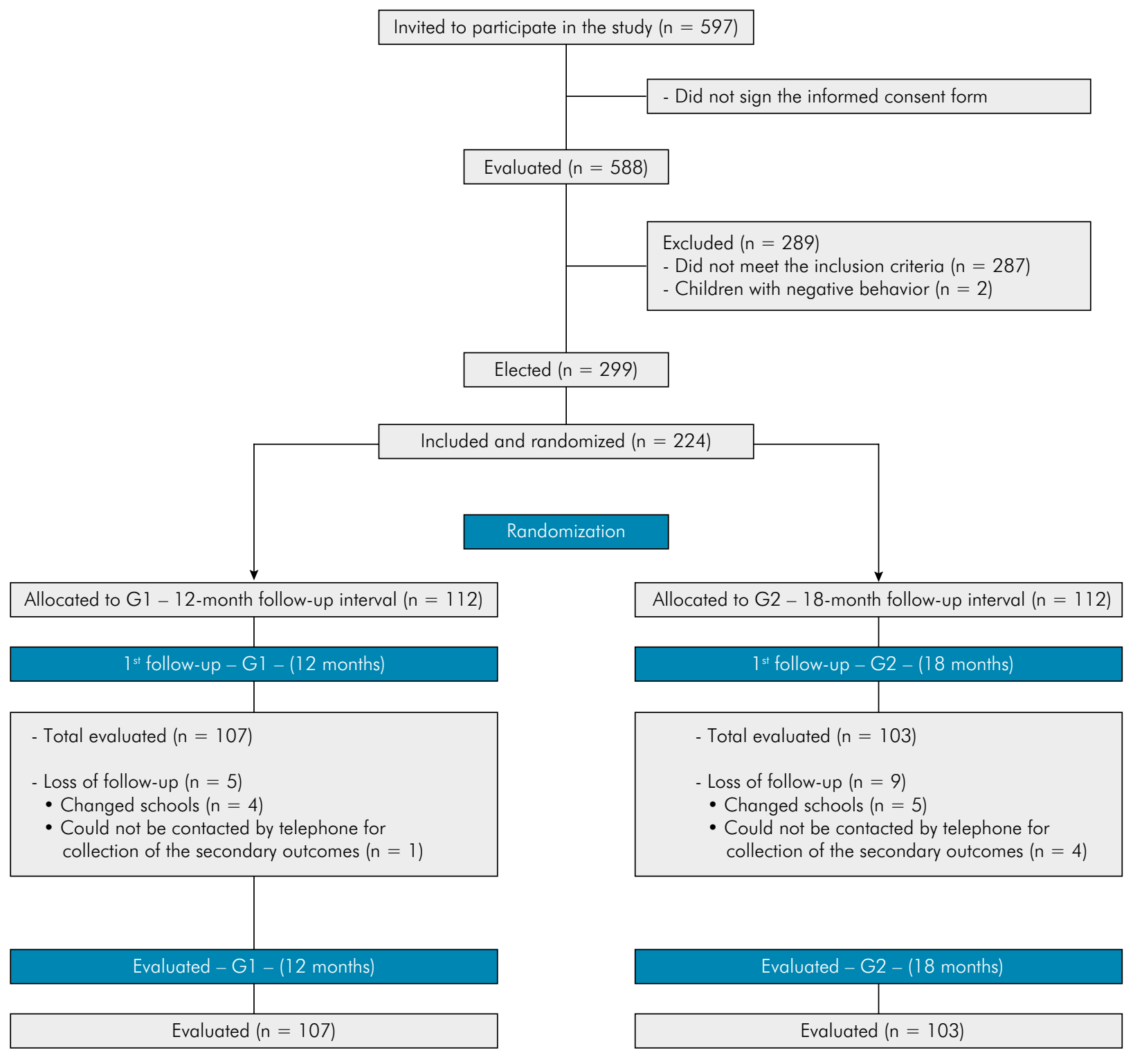

Figure. Flowchart of inclusion of the children in the sample. 


\section{Characteristics of the participants at baseline}

Table 1 shows the characteristics of all participants at baseline. A total of $52.7 \%$ were girls and $47.3 \%$ were boys; $77.7 \%$ lived in a nuclear family, and $67.9 \%$ had one or more siblings. It was reported in the interviews that a total of $71.4 \%$ of children brushed their teeth with fluoride toothpaste at concentrations of over $1000 \mathrm{ppm}$.

Dental caries, dental plaque, and gingival bleeding were selection criteria in this study, and the children included in the study were at low risk of caries at baseline (no caries lesions, no gingival bleeding, and low plaque score below 1). Consequently, the presence of plaque at baseline was $0.860 \pm 0.2421$ (mean \pm standard deviation), whereas dental caries and gingival bleeding were zero (Table 1).

Table 2 shows the socioeconomic and clinical characteristics at baseline, considering those lost to follow-up and those remaining in the respective study groups, with no difference between the two $(p>0.05)$.

Table 1. Characteristics of randomized participants for the study groups at the baseline (G1 and G2).

\begin{tabular}{|c|c|c|c|}
\hline Characteristics & G1 - Follow-up 12 months $(n=112)$ & G2 - Follow-up 18 months $(n=112)$ & All children $(n=224)$ \\
\hline \multicolumn{4}{|l|}{ Gender, n (\%) } \\
\hline Female & $58(51.8)$ & $60(53.6)$ & $118(52.7)$ \\
\hline Male & $54(48.2)$ & $52(46.4)$ & $106(47.3)$ \\
\hline \multicolumn{4}{|l|}{ Who do you live with? n (\%) } \\
\hline Nuclear family & $82(73.2)$ & $92(82.1)$ & $174(77.7)$ \\
\hline Non-nuclear family & $30(26.8)$ & $20(17.9)$ & $50(22.3)$ \\
\hline \multicolumn{4}{|l|}{ Number of brothers, $\mathrm{n}(\%)$} \\
\hline No brothers & $34(30.4)$ & 38 (33.9) & $72(32.1)$ \\
\hline$\geq 1$ brothers & $78(69.6)$ & $74(66.1)$ & $152(67.9)$ \\
\hline \multicolumn{4}{|l|}{ Mother's schooling, n (\%) } \\
\hline$\leq 8$ years & $9(8)$ & $9(8)$ & $18(8)$ \\
\hline$>8$ years & $103(92)$ & $103(92)$ & $206(92)$ \\
\hline \multicolumn{4}{|l|}{ Father's schooling, n (\%) } \\
\hline$\leq 8$ years & $24(21.4)$ & $20(17.9)$ & $44(19.6)$ \\
\hline$>8$ years & $88(78.6)$ & $92(82.1)$ & $180(80.4)$ \\
\hline \multicolumn{4}{|l|}{ Dentifrice concentration, $\mathrm{n}(\%)$} \\
\hline From 1,000 ppm F & $84(75)$ & $76(67.9)$ & $160(71.4)$ \\
\hline Without fluoride or < a 1,000 ppmF & $7(6.3)$ & $3(2.7)$ & $10(4.5)$ \\
\hline Do not know & $21(18.8)$ & $33(29.5)$ & $54(24.1)$ \\
\hline \multicolumn{4}{|l|}{ Minimally effective brushing frequency, $\mathrm{n}(\%)$} \\
\hline Twice a day & $36(32.1)$ & $30(26.8)$ & $66(29.5)$ \\
\hline 1 or more than 3 times a day & $73(65.2)$ & $81(72.3)$ & $154(68.8)$ \\
\hline Do not know & $3(2.7)$ & $1(0.9)$ & $4(1.8)$ \\
\hline \multicolumn{4}{|l|}{ Income } \\
\hline Mean \pm SD & $2,170.67 \pm 2,164.49$ & $2,099.73 \pm 1,371.54$ & $2,135.20 \pm 1,808.208$ \\
\hline \multicolumn{4}{|l|}{ Dental caries } \\
\hline \multicolumn{4}{|l|}{$\mathrm{d} 1 \mathrm{ICDAS}($ Mean $\pm \mathrm{SD})$} \\
\hline $\mathrm{d} 2 \mathrm{ICDAS}($ Mean $\pm \mathrm{SD}$ ) & $0.00 \pm 0.000$ & $0.00 \pm 0.000$ & $0.00 \pm 0.000$ \\
\hline d3ICDAS (Mean \pm SD) & $0.00 \pm 0.000$ & $0.00 \pm 0.000$ & $0.00 \pm 0.000$ \\
\hline Dental plaque (Mean \pm SD) & $0.852 \pm 0.2537$ & $0.867 \pm 0.2309$ & $0.860 \pm 0.2421$ \\
\hline Gingival bleeding (Mean \pm SD) & $0.000 \pm 0.000$ & $0.000 \pm 0.000$ & $0.000 \pm 0.000$ \\
\hline
\end{tabular}


Table 2. Socioeconomic and clinical characteristics in the initial consultation of the children examined and of those who were lost during the follow-up period.

\begin{tabular}{|c|c|c|c|c|}
\hline Characteristics & $\begin{array}{l}\text { G1 - Follow-up } 12 \text { months } \\
(\mathrm{n}=107)\end{array}$ & $\begin{array}{l}\text { G2 - Follow-up } 18 \text { months } \\
(n=103)\end{array}$ & $\begin{array}{l}\text { Children lost in follow-up } \\
\qquad(\mathrm{n}=14)\end{array}$ & $p$-value \\
\hline \multicolumn{5}{|l|}{ Gender, n (\%) } \\
\hline Female & $57(51.8)$ & $53(48.2)$ & $8(57.1)$ & \multirow{2}{*}{$0.474^{*}$} \\
\hline Male & $50(50)$ & $50(50)$ & $6(42.9)$ & \\
\hline \multicolumn{5}{|l|}{ Who do you live with?, n (\%) } \\
\hline Nuclear family & 79 (48.5) & $84(51.5)$ & $11(78.6)$ & \multirow[b]{2}{*}{$0.617^{*}$} \\
\hline Family not nuclear & $28(59.6)$ & $19(40.4)$ & $3(21.4)$ & \\
\hline \multicolumn{5}{|l|}{ Number of brothers, $\mathrm{n}(\%)$} \\
\hline No Brothers & $34(49.3)$ & $35(50.7)$ & $3(21.4)$ & \multirow{2}{*}{$0.285^{*}$} \\
\hline$\geq 1$ brothers & $73(51.8)$ & $68(48.2)$ & $11(78.6)$ & \\
\hline \multicolumn{5}{|l|}{ Mother's schooling, n (\%) } \\
\hline$\leq 8$ years & 9 (52.9) & $8(47.1)$ & $1(7.1)$ & \multirow{2}{*}{$0.688^{*}$} \\
\hline$>8$ years & $98(50.8)$ & $95(49.2)$ & $13(92.9)$ & \\
\hline \multicolumn{5}{|l|}{ Father's schooling, n (\%) } \\
\hline$\leq 8$ years & $22(53.7)$ & $19(46.3)$ & $3(21.4)$ & \multirow{2}{*}{$0.543^{*}$} \\
\hline$>8$ years & $85(50.3)$ & $84(49.7)$ & $11(78.6)$ & \\
\hline \multicolumn{5}{|l|}{ Dentifrice concentration, $\mathrm{n}(\%)$} \\
\hline From 1,000 ppm F & $80(53.7)$ & $69(46.3)$ & $11(78.6)$ & \multirow{3}{*}{$0.422^{* *}$} \\
\hline Without fluoride or < a 1,000 ppmF & $7(70)$ & $3(30)$ & - & \\
\hline Do not know & $20(39.2)$ & $31(60.8)$ & $3(21.4)$ & \\
\hline \multicolumn{5}{|l|}{ Minimally effective brushing frequency $\mathrm{n}(\%)$} \\
\hline Twice a day & $34(54)$ & $29(46)$ & $3(21.4)$ & \\
\hline 1 or more than 3 times a day & $70(49)$ & $73(51)$ & $11(78.6)$ & \\
\hline Do not know & $3(75)$ & $1(25)$ & - & $0.424^{* *}$ \\
\hline \multicolumn{5}{|l|}{ Income } \\
\hline Mean \pm SD & $2,190.79 \pm 2,207.265$ & $2,108.45 \pm 1,369.158$ & $1,907.14 \pm 1,251.131$ & $0.869^{* * *}$ \\
\hline \multicolumn{5}{|l|}{ Dental Caries } \\
\hline \multicolumn{5}{|l|}{ d 1 ICDAS active (Mean \pm SD) } \\
\hline $\mathrm{d} 2 \mathrm{ICDAS}($ Mean $\pm \mathrm{SD})$ & $0.00 \pm 0.000$ & $0.00 \pm 0.000$ & $0.00 \pm 0.000$ & \\
\hline $\mathrm{d} 3 \mathrm{ICDAS}($ Mean $\pm \mathrm{SD}$ ) & $0.00 \pm 0.000$ & $0.00 \pm 0.000$ & $0.00 \pm 0.000$ & $1.000^{* * *}$ \\
\hline Dental plaque (Mean \pm SD) & $0.852 \pm 0.2571$ & $0.868 \pm 0.2298$ & $0.856 \pm 0.2266$ & $0.812^{* * *}$ \\
\hline Gingival bleeding (Mean \pm SD) & $0.00 \pm 0.000$ & $0.00 \pm 0.000$ & $0.00 \pm 0.000$ & $1.000^{* * *}$ \\
\hline
\end{tabular}

${ }^{*}$ Chi-square test; ${ }^{* *}$ Exact Fisher test; ${ }^{* * *}$ Mann-Whitney test.

\section{Incidence of tooth decay in the groups}

At the follow-up examination, from the 107 children evaluated in G1, 7 showed incidence of active initial non-cavitated caries lesions (d1), 8 showed incidence of initial cavitated enamel lesions and/or shadow on dentin (d2), and 6 showed incidence of cavitated dentin lesions (d3). From the 103 children evaluated in G2, 18 were assessed as $\mathrm{d} 1,12$ as $\mathrm{d} 2$, and 9 as $\mathrm{d} 3$. Statistically significant difference $(p=0.012)$ was observed between $G 1$ and
G2 for active non-cavitated initial caries lesions (d1), but not for $\mathrm{d} 2$ or $\mathrm{d} 3$ (Table 3 ).

\section{Poisson regression analyses}

Table 4 shows the adjusted and unadjusted Poisson Regression analysis of the variables associated with the incidence of new active non-cavitated caries lesions (active $\mathrm{d} 1)(\mathrm{n}=210)$. The unadjusted model suggests that the risk of developing new active initial caries lesions $(p<0.05)$ is associated with the 
Table 3. Comparison between the groups at the end of the study.

\begin{tabular}{|c|c|c|c|}
\hline Outcomes & G1 - Follow-up 12 months $(n=107)$ & G2 - Follow-up 18 months $(n=103)$ & $p$-value \\
\hline \multicolumn{4}{|l|}{ Dental caries } \\
\hline dl ICDAS active (Mean \pm SD) & $0.10 \pm 0.433$ & $0.41 \pm 1.070$ & $0.012^{*}$ \\
\hline d2ICDAS (Mean $\pm S D)$ & $0.09 \pm 0.351$ & $0.20 \pm 0.662$ & $0.282^{*}$ \\
\hline d3ICDAS (Mean \pm SD) & $0.08 \pm 0.367$ & $0.15 \pm 0.513$ & $0.372^{*}$ \\
\hline \multicolumn{4}{|l|}{ Caries incidence d IICDAS, n (\%) } \\
\hline No & $100(54.1)$ & $85(45.9)$ & \multirow{2}{*}{$0.012^{* *}$} \\
\hline Yes & 7 (28) & $18(72)$ & \\
\hline \multicolumn{4}{|l|}{ Caries Incidence d2ICDAS, n (\%) } \\
\hline No & $99(52.1)$ & $91(47.9)$ & \multirow{2}{*}{$0.214^{* *}$} \\
\hline Yes & $8(40)$ & $12(60)$ & \\
\hline \multicolumn{4}{|l|}{ Caries incidence d3ICDAS, n (\%) } \\
\hline No & $101(51.8)$ & $94(48.2)$ & \multirow{2}{*}{$0.270^{* *}$} \\
\hline Yes & $6(40)$ & $9(60)$ & \\
\hline
\end{tabular}

fluoride concentration in the toothpastes and the brushing frequency at baseline, as well as the study group, the fluoride concentration in the toothpastes at follow-up, and the gingival bleeding and plaque index at follow-up. The final adjusted model showed that children from non-nuclear families $(\mathrm{RR}=2.56$; $p=0.007)$, with more than one sibling $(R R=2.53$; $\mathrm{p}=0.037)$, and using toothpaste without fluoride or with low concentrations at baseline $(\mathrm{RR}=3.91$; $\mathrm{p}=0.012$ ) were at a higher risk of developing active initial caries lesions (d1). In the follow-up consultation, children who belonged to $\mathrm{G} 2$ were at a higher risk of developing active initial lesions $(R R=2.37 ; p=0.047)$ compared to G1, and also those who presented a higher plaque index at the follow-up consultation $(\mathrm{RR}=3.14 ; \mathrm{p}<0.001)$.

Table 5 shows the adjusted and unadjusted Poisson Regression analysis of the variables associated with the incidence of new active cavitated dentin caries (d3) $(n=210)$. The unadjusted model showed that brushing frequency at baseline and a higher number of teeth with active initial lesions in the follow-up consultations were associated with a greater risk of developing new cavitated dentin caries $(p<0.05)$. In the adjusted model, it may be noted that children who had a higher number of teeth with active initial lesions in the follow-up consultations were at a higher risk of developing cavitated dentin caries $(\mathrm{RR}=1.62 ; \mathrm{p}=0.001)$.

\section{Discussion}

There is a pressing need for more scientific evidence on the ideal follow-up interval between dental consultations. Since a systematic review ${ }^{1}$ found no conclusive evidence on the subject in adult patients and children, the present study sought to fill this gap in the literature on preschoolers.

This randomized trial evaluated the effectiveness of 12 and 18-month follow-up intervals between dental consultations in terms of incidence of caries lesions, both follow-up intervals are justifiable regarding cavitated dentin caries.

By observing the statistical analyzes of the present study, a higher risk of developing initial caries lesions was found for patients in the 18-month follow-up interval group. However, such lesions can be treated using just preventive measures such as fluoride toothpaste in conventional concentration $(\geq 1,000 \mathrm{ppmF})$ and low intake of sugary food..$^{18,19,20}$

It is important to note that patients classified as low risk of caries at the time of the initial consultation might have had a change in oral hygiene and dietary habits between consultations as all caregivers were advised about these habits after each follow-up visit.

Population studies have been suggesting that it is possible to increase the follow-up intervals between public dental appointment for children with a low caries risk due to the slower progression and low 
Table 4. Adjusted and unadjusted Poisson Regression analysis of the variables associated with the incidence of new active non-cavitated caries lesions (active d1 ICDAS) $(n=210)$.

\begin{tabular}{|c|c|c|c|c|c|}
\hline \multirow{2}{*}{ Covariables } & & \multicolumn{2}{|c|}{ Unadjusted model } & \multicolumn{2}{|c|}{ Adjusted model } \\
\hline & & $\operatorname{RR}(95 \% \mathrm{Cl})$ & $\mathrm{p}$-value & $\mathrm{RR}(95 \% \mathrm{Cl})$ & $p$-value \\
\hline \multicolumn{6}{|l|}{ Baseline condition } \\
\hline \multicolumn{6}{|l|}{ Gender } \\
\hline \multicolumn{6}{|l|}{ Female } \\
\hline Male & & $0.73(0.34-1.56)$ & 0.421 & & \\
\hline \multicolumn{6}{|l|}{ Who do you live with? } \\
\hline \multicolumn{6}{|l|}{ Nuclear family } \\
\hline Family not nuclear & & $1.95(0.92-4.13)$ & 0.081 & $2.56(1.28-5.10)$ & 0,007 \\
\hline \multicolumn{6}{|l|}{ Number of brothers } \\
\hline \multicolumn{6}{|l|}{ No Brothers } \\
\hline$\geq 1$ brothers & & $1.95(0.76-5.00)$ & 0.161 & $2.53(1.05-6.05)$ & 0,037 \\
\hline \multicolumn{6}{|l|}{ Mother's schooling } \\
\hline \multicolumn{6}{|l|}{$\leq 8$ years } \\
\hline$>8$ years & & $1.01(0.26-3.95)$ & 0.985 & & \\
\hline \multicolumn{6}{|l|}{ Father's schooling } \\
\hline \multicolumn{6}{|l|}{$\leq 8$ years } \\
\hline$>8$ years & & $0.81(0.45-1.47)$ & 0.507 & & \\
\hline \multicolumn{6}{|l|}{ Dentifrice concentration } \\
\hline \multicolumn{6}{|l|}{ From 1,000 ppm F } \\
\hline \multicolumn{2}{|l|}{ Without fluoride or $<$ a 1,000 ppmF } & 3.19 (1.09-9.33) & 0.034 & $3.91(1.35-11.31)$ & 0.012 \\
\hline \multicolumn{2}{|l|}{ Do not know } & $1.67(0.74-3.75)$ & 0.215 & $1.52(0.72-3.23)$ & 0.270 \\
\hline \multicolumn{6}{|l|}{ Minimum effective brushing frequency } \\
\hline \multicolumn{6}{|l|}{ Twice a day } \\
\hline \multicolumn{2}{|l|}{1 or more than 3 times a day } & $1.13(0.49-2.58)$ & 0.766 & & \\
\hline \multicolumn{2}{|l|}{ Do not know } & $2.48(7.42-8.29)$ & $<0.001$ & & \\
\hline \multicolumn{6}{|l|}{ Monthly family income } \\
\hline \multicolumn{6}{|l|}{ Below the median ( $R \$ 1,800.00)$} \\
\hline Above the median & & $1.10(0.52-2.31)$ & 0.792 & & \\
\hline Dental plaque & & $1.10(0.20-5.88)$ & 0.909 & & \\
\hline Conditions during return visits ${ }^{*}$ & & & & & \\
\hline Return group & & & & & \\
\hline 12 months & & & & & \\
\hline 18 months & & $2.67(1.16-6.14)$ & 0.021 & $2.37(1.01-5.56)$ & 0.047 \\
\hline Dentifrice concentration & $\mathrm{n}(\%)$ & & & & \\
\hline From 1,000 ppm F & $112(53.3)$ & & & & \\
\hline Without fluoride or $<$ a 1,000 ppmF & $34(16.1)$ & $2.39(1.04-5.48)$ & 0.039 & & \\
\hline Do not Know & $64(30.4)$ & $0.95(0.36-2.46)$ & 0.923 & & \\
\hline Minimally effective brushing frequency & n (\%) & & & & \\
\hline Twice a day & $77(36,6)$ & & & & \\
\hline 1 or more than 3 times a day & $129(61,4)$ & $0.83(0.39-1.79)$ & 0.645 & & \\
\hline Do not know & $4(1,9)$ & $1.92(0.32-11.61)$ & 0.475 & & \\
\hline Gingival bleeding & & $3.30(1.80-6.07)$ & $<0.001$ & & \\
\hline Dental plaque index & & $3.28(2.17-4.98)$ & $<0.001$ & $3.14(2.12-4.64)$ & $<0.001$ \\
\hline
\end{tabular}


Follow-up interval for dental appointments: a randomized clinical trial with children with low caries risk

Table 5. Adjusted and unadjusted Poisson Regression analysis of the variables associated with the incidence of new active cavitated dentin caries (d3ICDAS) ( $\mathrm{n}=210)$.

\begin{tabular}{|c|c|c|c|c|c|}
\hline \multirow{2}{*}{ Covariables } & & \multicolumn{2}{|c|}{ Unadjusted model } & \multicolumn{2}{|c|}{ Adjusted model } \\
\hline & & $\operatorname{RR}(95 \% \mathrm{Cl})$ & $p$-value & $\operatorname{RR}(95 \% \mathrm{Cl})$ & p-value \\
\hline \multicolumn{6}{|l|}{ Baseline condition } \\
\hline \multicolumn{6}{|l|}{ Gender } \\
\hline \multicolumn{6}{|l|}{ Female } \\
\hline Male & & $1.25(0.47-3.35)$ & 0.647 & & \\
\hline \multicolumn{6}{|l|}{ Who do you live with? } \\
\hline \multicolumn{6}{|l|}{ Nuclear family } \\
\hline Family not nuclear & & $0.86(0.25-2.95)$ & 0.820 & & \\
\hline \multicolumn{6}{|l|}{ Number of brothers } \\
\hline \multicolumn{6}{|l|}{ No Brothers } \\
\hline$\geq 1$ brothers & & $1.95(0.57-6.72)$ & 0.286 & & \\
\hline \multicolumn{6}{|l|}{ Mother's schooling } \\
\hline \multicolumn{6}{|l|}{$\leq 8$ years } \\
\hline$>8$ years & & $1.23(0.17-8.86)$ & 0.835 & & \\
\hline \multicolumn{6}{|l|}{ Father's schooling } \\
\hline \multicolumn{6}{|l|}{$\leq 8$ years } \\
\hline$>8$ years & & $1.21(0.53-2.76)$ & 0.646 & & \\
\hline \multicolumn{6}{|l|}{ Dentifrice concentration } \\
\hline \multicolumn{6}{|l|}{ From 1,000 ppm F } \\
\hline \multicolumn{2}{|l|}{ Without fluoride or $<$ a 1,000 ppmF } & $1.65(0.23-11.86)$ & 0.616 & & \\
\hline \multicolumn{2}{|l|}{ Do not know } & $1.62(0.57-4.63)$ & 0.365 & & \\
\hline \multicolumn{6}{|l|}{ Minimally effective brushing frequency } \\
\hline \multicolumn{6}{|l|}{ Twice a day } \\
\hline \multicolumn{2}{|l|}{1 or more than 3 times a day } & $1.21(0.40-3.67)$ & 0.734 & & \\
\hline \multicolumn{2}{|l|}{ Do not know } & $2.60(6.62-1.02)$ & $<0.001$ & & \\
\hline \multicolumn{6}{|l|}{ Monthly family income } \\
\hline Below the median ( $\mathrm{R} \$ 1,800.00)$ & & & & & \\
\hline Above the median & & $2,04(0,72-5,77)$ & 0,18 & & \\
\hline Dental plaque & & $0,66(0,09-4,50)$ & 0,678 & & \\
\hline Conditions during return visits" & & & & & \\
\hline Return group & & & & & \\
\hline 12 months & & & & & \\
\hline 18 months & & $1.56(0.57-4.23)$ & 0.384 & $1.08(0.36-3.29)$ & 0.883 \\
\hline Dental caries & & & & & \\
\hline Number of teeth d1 ICDAS active & & $1.64(1.28-2.09)$ & $<0.001$ & $1.62(1.23-2.15)$ & 0.001 \\
\hline Number of teeth d2ICDAS & & & & & \\
\hline Dentifrice concentration & $\mathrm{n}(\%)$ & & & & \\
\hline From 1,000 ppm F & $112(53.3)$ & & & & \\
\hline Without fluoride or $<$ a 1,000 ppmF & $34(16.1)$ & $1.88(0.58-6.06)$ & 0.289 & & \\
\hline Do not know & $64(30.4)$ & $1(0.30-3.29)$ & 1.000 & & \\
\hline Minimally effective brushing frequency & $n(\%)$ & & & & \\
\hline Twice a day & $77(36.6)$ & & & & \\
\hline 1 or more than 3 times a day & $129(61.4)$ & $0.59(0.21-1.64)$ & 0.317 & & \\
\hline Do not know & $4(1.9)$ & $2.75(0.43-17.36)$ & 0.282 & & \\
\hline Gingival bleeding & & $1.54(0.67-3.53)$ & 0.302 & & \\
\hline Dental plaque & & $1.42(0.61-3.30)$ & 0.415 & & \\
\hline
\end{tabular}


annual increase of the incidence of caries. ${ }^{21,22} \mathrm{It}$ corroborates the results that the 18-month interval can also be used, since initial caries lesions are remineralizable through changes in oral health habits and do not need to be restored. Furthermore, it can be observed that even though significant differences between the 12 and 18-month follow-up intervals in relation to active initial lesions exist, children of both groups developed these lesions ( 7 and 18 children of the 12 and 18-month follow-up groups, respectively). This could indicate, at the clinical level, that the control of patients' oral health habits is difficult for the professional, independent of the follow-up interval, since it is the responsibility of the child's caregiver.

The adjusted regression analyses showed that children inserted in non-nuclear families and with more than one sibling were at a higher risk of developing active initial caries lesions. Taking into consideration that children's oral health care habits, especially of preschoolers, require the guardian's dedication, they could become more effective when shared by the father and mother (nuclear family). Children in non-nuclear families and with more than one sibling could effectively be at greater risk of developing new active initial caries lesions.

The use of incorrect fluoride concentrations at the baseline further increased the risk of the children developing active initial lesions in the follow-up consultation. In this sense, the prevention of tooth decay in children is based on oral health care, especially dental biofilm control by using fluoridated toothpaste at concentrations equal or higher than 1,000 ppm and following the advice of reducing sucrose consumption. ${ }^{18,19,20}$ In the present study, though some of the children's guardians reported using toothpastes with concentrations different than those effective for the prevention of caries at the baseline, the whole sample was told to use toothpaste fluoridated at 1,100 ppmF during the research. Thus, it is possible that the association between the use of toothpastes with incorrect fluoride concentrations at the baseline and the increase in the risk of developing active initial lesions was due to the lack of control of the daily sucrose consumption, as it was not measured quantitatively in this study. It is known that food preferences, such as sugar consumption, in the first years of life, have been strongly correlated to food preferences in late childhood. ${ }^{23}$

Children who had a greater number of teeth with active initial lesions in the follow-up consultations were at a higher risk of developing new cavitated dentin caries (active d3ICDAS). This result was expected and confirmed the results of previous studies on primary teeth, where initial caries lesions were predictive factors for the development of new initial or cavitated lesions. ${ }^{14,24,25}$

The findings mentioned above are challenging, indicating that a child with low risk of tooth decay at baseline can present dental caries in the follow-up consultation, regardless of the follow-up interval adopted, in other words, that the risk of caries is dynamic. Thus, future studies focused on preschoolers with low risk of caries should consider other behavioral risk factors that were not explored in this study to better understand the dynamics of the risk of caries in this population. A recent systematic review identified the most relevant risk factors associated with early childhood caries, which were enamel defects, presence of dentinal caries, and high levels of mutans streptococci. ${ }^{26}$ Interestingly, our participants neither presented enamel defects or dentinal caries (exclusion criteria), and were considered low risk patients. The caries incidence in our study sample was, therefore, most probably due to high levels of mutans, reflected in the plaque index during the follow-up examination, which was significantly associated with d1ICDAS, and the presence of plaque, in turn, was significantly associated with more severe lesions (d3ICDAS).

A randomized clinical trial ${ }^{3}$ noted that a 24 -month follow-up interval was associated with a greater increase in the number of cavitated caries lesions in primary teeth in comparison to a 12-month interval, but no statistically significant differences were observed between the groups. The authors suggested extending the follow-up intervals and argued that this would allow the correct distribution and targeting of the human and financial resources.

In addition, a systematic review ${ }^{1}$ on the effectiveness of follow-up intervals indicates that the randomized clinical trial ${ }^{3}$ mentioned before shows some risk of bias and low quality scientific evidence. This trial ${ }^{3}$ did not mention a series of factors, such as sample calculation, 
blinding of the examiners and participants, random sequence generation method and allocation of the participants to each group. In addition, the criteria used for classification of the patients' risk were not clear. Contrarily, the present study considered all the mentioned aspects in its methodological design.

The choice of two different follow-up intervals in the present study was based on the results of three studies: a) a systematic review, ${ }^{1}$ where the 12 or 24-month follow-up intervals were not different in relation to the incidence of cavitated dental caries, b) a cross-sectional study, ${ }^{22}$ which proposed 24-month follow-up intervals for children with low caries incidence; c) a retrospective cohort study, ${ }_{1}^{14}$ where the incidence of active initial caries lesions was observed even in the 12-month interval. Considering the different intervals described in the literature, and with the aim of focusing on health promotion, the 24-month interval was deemed too long for the prevention of tooth decay, so we decided to adopt the 12- and 18-month follow-up intervals between dental consultations.

The small drop-out rate $(6.25 \%)$ was another positive aspect of our study, being considered very small and thus ensuring the good quality of the comparison between the groups. Similarly, no statistical difference in socioeconomic and clinical characteristics was found between the children examined and those who dropped-out, also confirming the good quality of the study design.

The limitation of the study was that data collection was carried out in the public schools of São Paulo, while the dental office would be ideal. Nevertheless, this allowed observing the development of the dental caries in a real life scenario of a representative population that had not sought dental services for prevention. Conducting the consultations in a dental office would have selected children at low risk of caries who had received some preventive treatment, which could have resulted in a lower incidence of caries throughout the study, underestimating the effect of follow-up intervals. Moreover, despite the study being conducted in São Paulo, its results can easily benefit other health systems, not only within Brazil, but also in other developing countries whose society face similar socio-economic and healthrelated challenges.

In addition, the study could have benefited even more from the daily control of sugar consumption, as diet is the main causal factor of caries. A systematic review showed a consistent evidence of the relationship between the amount of sugar consumed, mainly sucrose, and the development of dental caries. ${ }^{27}$ However, all the children and their guardians were advised at the baseline and in the follow-up consultations to reduce the consumption of sugar to 4 times daily. The guardians were also given information about the damages to the children's oral and general health caused by consumption greater than the one recommended.

\section{Conclusion}

The 12-month and 18-month follow-up intervals are justifiable. Although significantly more initial active caries lesions were found with the 18-month follow-up interval, these lesions can be treated using preventive measures and risk monitoring. Besides, no difference was found in incidence of cavitated dentin lesions between the two intervals (12- or 18-month).

\section{References}

1. Riley P, Worthington HV, Clarkson JE, Beirne PV. Recall intervals for oral health in primary care patients. Cochrane Database Syst Rev. 2013 Dec;12(12):CD004346. https://doi.org/10.1002/14651858.CD004346.pub4

2. Davenport CF, Elley KM, Fry-Smith A, Taylor-Weetman CL, Taylor RS. The effectiveness of routine dental checks: a systematic review of the evidence base. Br Dent J. 2003 Jul;195(2):87-98. https://doi.org/10.1038/sj.bdj.4810337

3. Wang N, Marstrander P, Holst D, Ovrum L, Dahle T. Extending recall intervals: effect on resource consumption and dental health. Community Dent Oral Epidemiol. 1992 Jun;20(3):122-4. https://doi.org/10.1111/j.1600-0528.1992.tb01544.x

4. Tellez M, Gomez J, Pretty I, Ellwood R, Ismail Al. Evidence on existing caries risk assessment systems: are they predictive of future caries? Community Dent Oral Epidemiol. 2013 Feb;41(1):67-78. https://doi.org/10.1111/cdoe.12003 
5. Mejàre I, Axelsson S, Dahlén G, Espelid I, Norlund A, Tranæus S, et al. Caries risk assessment. A systematic review. Acta Odontol Scand. 2014 Feb;72(2):81-91. https://doi.org/10.3109/00016357.2013.822548

6. Moher D, Hopewell S, Schulz KF, Montori V, Gøtzsche PC, Devereaux PJ, et al. CONSORT 2010 Explanation and elaboration: updated guidelines for reporting parallel group randomised trials [Erratum in: J Clin Epidemiol. 2012;65] [3]. J Clin Epidemiol. 2010 Aug;63(8):e1-37. https://doi.org/10.1016/i.jclinepi.2010.03.004

7. Löe H. The Gingival Index, the Plaque Index and the Retention Index Systems. J Periodontol. 1967 Nov-Dec;38(6 Suppl):610-6. https://doi.org/10.1902/jop.1967.38.6.610

8. Greene JC, Vermillion JR. The simplified oral hygiene index. J Am Dent Assoc. 1964 Jan;68(1):7-13. https://doi.org/10.14219/jada.archive.1964.0034

9. Pitts N. "ICDAS": an international system for caries detection and assessment being developed to facilitate caries epidemiology, research and appropriate clinical management. Community Dent Health. 2004 Sep;21(3):193-8.

10. Ismail Al, Sohn W, Tellez M, Amaya A, Sen A, Hasson H, et al. The International Caries Detection and Assessment System (ICDAS): an integrated system for measuring dental caries. Community Dent Oral Epidemiol. 2007 Jun;35(3):170-8. https://doi.org/10.1111/j.1600-0528.2007.00347.x

11. Ekstrand KR, Martignon S, Ricketts DJ, Qvist V. Detection and activity assessment of primary coronal caries lesions: a methodologic study. Oper Dent. 2007 May-Jun;32(3):225-35. https://doi.org/10.2341/06-63

12. Braga MM, Mendes FM, Ekstrand KR. Detection activity assessment and diagnosis of dental caries lesions. Dent Clin North Am. 2010 Jul;54(3):479-93. https://doi.org/10.1016/j.cden.2010.03.006

13. São Paulo. Secretaria Municipal da Saúde. Diretrizes para a atenção em saúde buccal: crescendo e vivendo com saúde bucal. São Paulo: Secretaria da Saúde; 2012 [citado 18 abril 2016]. Disponível em: http://www.prefeitura.sp.gov.br/cidade/secretarias/upload/ saude/arquivos/saudebucal/Diretrizes_Saude_Bucal_2012.pdf

14. Abanto J, Celiberti P, Braga MM, Vidigal EA, Cordeschi T, Haddad AE, et al. Effectiveness of a preventive program based on caries risk assessment and recall intervals on the incidence and regression of initial caries lesions in children. Int J Paediatr Dent. 2015 Jul;25(4):291-9. https://doi.org/10.1111/ipd.12144

15. Oliveira BH, Salazar M, Carvalho DM, Falcão A, Campos K, Nadanovsky P. Biannual fluoride varnish applications and caries incidence in preschoolers: a 24 -month follow-up randomized placebo-controlled clinical trial. Caries Res. 2014;48(3):228-36. https://doi.org/10.1159/000356863

16. Klaassen MA, Veerkamp JS, Hoogstraten J. Young children's oral health-related quality of life and dental fear after treatment under general anaesthesia: a randomized controlled trial. Eur J Oral Sci. 2009 Jun;117(3):273-8. https://doi.org/10.1111/j.1600-0722.2009.00627.x

17. Gaynor WN, Thomson WM. Changes in young children's OHRQoL after dental treatment under general anaesthesia. Int J Paediatr Dent. 2012 Jul;22(4):258-64. https://doi.org/10.1111/j.1365-263X.2011.01190.x

18. Kidd E, Fejerskov O. Changing concepts in cariology: forty years on. Dent Update. 2013 May;40(4):277-8. https://doi.org/10.12968/denu.2013.40.4.277

19. Santos AP, Nadanovsky P, Oliveira BH. A systematic review and meta-analysis of the effects of fluoride toothpastes on the prevention of dental caries in the primary dentition of preschool children. Community Dent Oral Epidemiol. 2013 Feb;41(1):1-12. https://doi.org/10.1111/j.1600-0528.2012.00708.x

20. Wright JT, Hanson N, Ristic H, Whall CW, Estrich CG, Zentz RR. Fluoride toothpaste efficacy and safety in children younger than 6 years: a systematic review. J Am Dent Assoc. 2014 Feb;145(2):182-9. https://doi.org/10.14219/jada.2013.37

21. Lahti SM, Hausen HW, Widström E, Eerola A. Intervals for oral health examinations among Finnish children and adolescents: recommendations for the future. Int Dent J. 2001 Apr;51(2):57-61. https://doi.org/10.1002/j.1875-595X.2001.tb00822.x

22. Tan $\mathrm{EH}$, Batchelor $\mathrm{P}$, Sheiham A. A reassessment of recall frequency intervals for screening in low caries incidence populations. Int Dent J. 2006 Oct;56(5):277-82. https://doi.org/10.1111/j.1875-595X.2006.tb00101.x

23. Skinner JD, Carruth BR, Wendy B, Ziegler PJ. Children's food preferences: a longitudinal analysis. J Am Diet Assoc. 2002 Nov;102(11):1638-47. https://doi.org/10.1016/S0002-8223(02)90349-4

24. Kramer ACA, Skeie MS, Skaare AB, Espelid I, Ostberg AL. Caries increment in primary teeth from 3 to 6 years of age: a longitudinal study in Swedish children. Eur Arch Paediatr Dent. 2014 Jun;15(3):167-73. https://doi.org/10.1007/s40368-013-0079-7

25. Guedes RS, Piovesan C, Ardenghi TM, Emmanuelli B, Braga MM, Ekstrand KR, et al. Validation of visual caries activity assessment: $A$ 2-yr cohort study. J Dent Res. 2014 Jul;93(7 Suppl):101S-7S. https://doi.org/10.1177/0022034514531017

26. Kirthiga M, Murugan M, Saikia A, Kirubakaran R. Risk factors for early childhood caries: a systematic review and meta-analysis of case control and cohort studies. Pediatr Dent. 2019 Mar;41(2):95-112.

27. Moynihan PJ, Kelly SA. Effect on caries of restricting sugars intake: systematic review to inform WHO guidelines. J Dent Res.

2014 Jan;93(1):8-18. https://doi.org/10.1177/0022034513508954 